\title{
BMJ
}

\section{Inequalities in reported use of breast and cervical screening in Great Britain: analysis of cross sectional survey data}

\author{
Kath Moser, senior researcher, ${ }^{1}$ Julietta Patnick, visiting professor, ${ }^{1}$ director, ${ }^{2}$ Valerie Beral, director ${ }^{1}$
} ${ }^{1}$ Cancer Epidemiology Unit,
University of Oxford, Oxford OX3 7LF

${ }^{2}$ NHS Cancer Screening Programmes, Fulwood House, Sheffield S10 3TH

Correspondence to: $\mathrm{K}$ Moser

kath.moser@ceu.ox.ac.uk

Cite this as: BMJ 2009;338:b2025 doi:10.1136/bmj.b2025

\author{
ABSTRACT \\ Objective To investigate the relation between women's \\ reported use of breast and cervical screening and \\ sociodemographic characteristics. \\ Design Cross sectional multipurpose survey. \\ Setting Private households, Great Britain. \\ Population 3185 women aged 40-74 interviewed in the \\ National Statistics Omnibus Survey 2005-7.
}

Main outcome measures Ever had a mammogram, ever had a cervical smear, and, for each, timing of most recent screen.

Results $91 \%$ (95\% confidence interval $90 \%$ to $92 \%$ ) of women aged 40-74 years reported ever having had a cervical smear, and $93 \%$ (92\% to $94 \%$ ) of those aged 53-74 years reported ever having had a mammogram; $3 \%$ ( $2 \%$ to $4 \%$ ) of women aged $53-74$ years had never had either breast or cervical screening. Women were significantly more likely to have had a mammogram if they lived in households with cars (compared with no car: one car, odds ratio $1.67,95 \%$ confidence interval 1.06 to

2.62; two or more cars, odds ratio $2.65,1.34$ to 5.26), and in owner occupied housing (compared with rented housing: own with mortgage, odds ratio $2.12,1.12$ to 4.00; own outright, odds ratio $2.19,1.39$ to 3.43 ), but no significant differences by ethnicity, education,

occupation, or region were found. For cervical screening, ethnicity was the most important predictor; white British women were significantly more likely to have had a cervical smear than were women of other ethnicity (odds ratio $2.20,1.41$ to 3.42 ). Uptake of cervical screening was greater among more educated women but was not significantly associated with cars, housing tenure, or region.

Conclusions Most (84\%) eligible women report having had both breast and cervical screening, but $3 \%$ report never having had either. Some inequalities exist in the reported use of screening, which differ by screening type; indicators of wealth were important for breast screening and ethnicity for cervical screening. The routine collection within general practice of additional sociodemographic information would aid monitoring of inequalities in screening coverage and inform policies to correct them.

\section{INTRODUCTION}

Breast screening and cervical screening have been shown to reduce mortality from cancer. ${ }^{1-4}$ The NHS cancer screening programmes invite women in England aged 50-70 (50-64 before 2001) for breast screening every three years and women aged 25-64 (20-64 before 2003) for cervical screening every three to five years (women aged 25-49 every three years, those aged 50-64 every five years). Statistics on the population coverage of the breast and cervical screening programmes for England are published annually. ${ }^{56}$ These data, supplied by primary care organisations, are derived from the NHS call and recall system, and as such are based on women ever in contact with the NHS, usually through registration with general practice. Although they are a rich source of information, these data do have important limitations, especially for investigating inequalities. As information on patients' ethnicity and socioeconomic characteristics is not routinely collected in general practice, little is known about the characteristics of women attending for screening and therefore how screening coverage varies across sociodemographic groups. ${ }^{78}$ However, some studies on inequalities in screening have used information other than that from routine administrative data. Some use nationally representative survey data and individual sociodemographic characteristics, ${ }^{910}$ but most are for small geographical areas and use measures of area deprivation (using either the woman's postcode of residence or the postcode of the general practice) rather than individual characteristics. ${ }^{11-13}$ A review of studies on inequalities in access to cancer screening published between 1998 and 2003 found a dearth of information relating to the United Kingdom. ${ }^{14}$ The 2007 Cancer Reform Strategy gives great importance to tackling inequalities in incidence of cancer and access to services and emphasises the need to improve the knowledge base. ${ }^{15}$

A further limitation of the routine statistics is that they are based on registered general practice lists and therefore can be affected by list inflation-that is, patients remain registered at a specific general practice despite having died, emigrated, or moved home. The use of practice lists inflated by such "ghost" patients can result in performance indicators and health promotion measures such as screening coverage being underestimated, ${ }^{16}$ with areas of high population mobility, such as London, being particularly affected. ${ }^{17}$ Furthermore, routine statistics cover breast and 


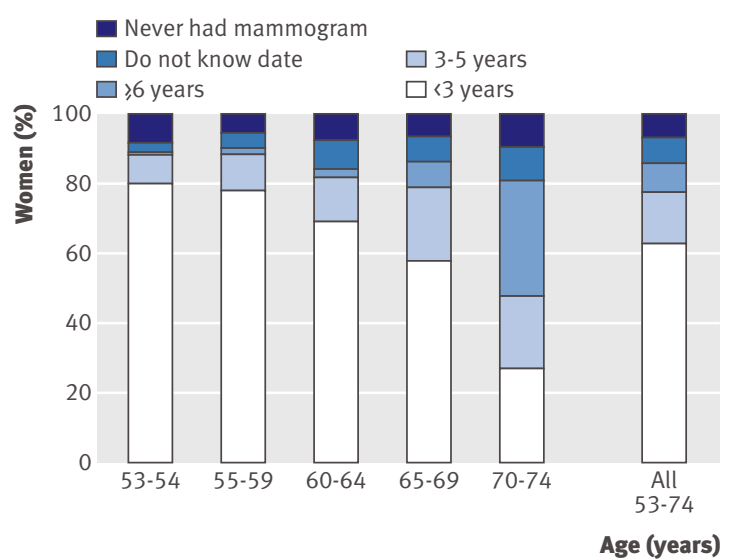

Fig 1| Time since most recent mammogram, all women aged 53-74

cervical screening separately and largely provide cross sectional estimates of coverage rather than information on women's lifetime use of screening.

By using data from a general population survey of Great Britain, we can overcome shortcomings in the routine data and contribute to the evidence base on inequalities in screening. We investigated the relation between women's reported use of breast and cervical screening and their individual and household sociodemographic characteristics.

\section{METHODS}

This study uses data from the women's health screening module of the National Statistics Omnibus Survey. This is a multipurpose survey with a probability cluster design, carried out monthly by the Office for National Statistics in a representative sample of adults living in private households in Great Britain. ${ }^{18}$ Each month a new sample of 67 postal sectors is selected with probability proportionate to size and stratified by region, socioeconomic classification, and the proportion of people aged over 65 . Within each sector, 30 addresses are chosen randomly and one adult member in each household is selected. Considerable efforts are made to interview that person (for example, households receive a letter in advance and at least four attempts are made to contact a household). Proxy interviews are not taken.

The screening module was included in nine surveys in total: four in 2005 (February, April, August, December), four in 2006 (March, June, September, December), and one in March 2007. It was administered to women aged 40-74 years. The module was commissioned by the NHS Breast Screening Programme Evaluation Group; VB and JP designed the questions. Respondents were asked "Have you ever had a mammogram (x-ray of your breasts)?" and "Have you ever had a cervical screening (the smear test or Pap test)?" Where applicable, women were asked the year and month of their most recent mammogram and also of their most recent cervical smear, as well as the reason for their most recent mammogram (selected from routine screening by the NHS Breast Screening Programme, NHS screening owing to family history of breast cancer, non-routine referral to the NHS, private examination, follow-up after breast cancer treatment, and other). Women were also asked if they had had a hysterectomy. The Omnibus Survey collects a range of demographic and socioeconomic information.

Response rates for the nine surveys ranged between $64 \%$ and $69 \%$ of the eligible sample; an additional $24 \%$ to $27 \%$ were refusals, and the remainder were non-contacts. Interviews were achieved for a total of $95 \%$ of the women eligible for the health screening module in these nine surveys. We combined the data from the nine surveys for analysis, giving responses from a total of 3185 women aged 40-74.

\section{Outcome measures}

The main outcome measures were ever having had a mammogram and ever having had a cervical smear. Using these items of information, we classified women into those who had had both types of screening (that is, at least one mammogram and at least one cervical smear), only one screening type (either a mammogram or a cervical smear but not both), and neither screening type. We adopted this approach because women who have had one type of screening are known to be more likely to attend another screening programme. In our sample, women who had had a cervical smear were more likely to have had a mammogram $(95 \%)$ than women who had not had a smear (77\%). Similarly, women who had had a mammogram were more likely to have also had a smear $(90 \%)$ than those who had not had a mammogram (63\%).

We also looked at the reason for the most recent mammogram among women who had ever had a mammogram and the time since most recent mammogram and time since most recent cervical smear. For these last two measures, our particular interest was in women who had had a mammogram in the previous three years or a cervical smear in the previous five years, as these are the intervals traditionally used for routine screening. We excluded women who had had

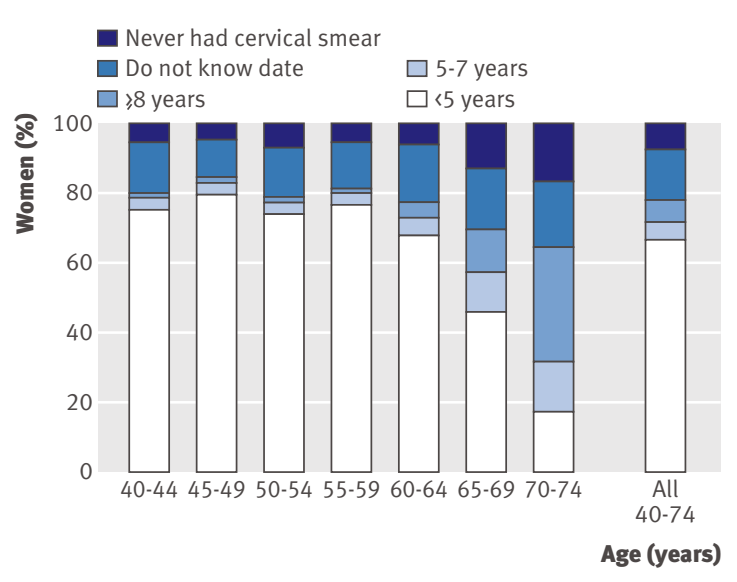

Fig 2 2 Time since most recent cervical smear, women aged 40-74 who had not had a hysterectomy 
a hysterectomy from the analysis of time since most recent cervical smear. We did not exclude them when looking at ever having had cervical screening, as hysterectomy is not common among very young women (in our sample 5.5\% of women aged 40-44 reported having had a hysterectomy, and $6.1 \%$ of hysterectomies were done before age 30), leaving time in which they could have had a smear before having a hysterectomy.

\section{Statistical analyses}

We used Stata statistical software, version 9.2, for all analyses. We used supplied weighting factors to correct for the unequal probability of selection resulting from only one adult per household being interviewed and to compensate for some non-response bias by calibrating the Omnibus Survey sample to Office for National Statistics population totals. ${ }^{18}$ The analysis took into account the impact on standard errors of clustering of interviews within postcode sectors, stratification, and probability weighting.

The analyses concerning only cervical screening included all women aged 40-74, as women are first invited for cervical screening in their 20s. However, we included only women aged 53-74 in the breast screening analyses; all women in this age group should have had at least one invitation for a mammogram, as women are first invited for routine mammography between the ages of 50 and 52 years. For the same reason, analyses involving both screening types focused on women aged 53-74. The two women who did not state whether they had ever had a mammogram or a cervical smear were omitted from all analyses. Women with missing values on any of the sociodemographic variables were omitted from the regression analyses (35 women in total: one missing on cars/vans, two on housing tenure, 32 on educational qualifications).

We used logistic regression to investigate relations between screening history and sociodemographic characteristics of the women, including the number of cars/ vans available to the household ( $0,1,2$ or more), housing tenure (rents, owns with mortgage, owns outright), highest level of education qualification (no qualifications, below degree level, degree or equivalent), National Statistics socioeconomic classification (routine and manual; intermediate; managerial and professional occupations; not classified including full time students, the long term unemployed, those who have never worked), ethnicity (other, white British), and region of residence (North, Midlands and East Anglia, London, South East, South West, Wales, Scotland). The categories used were determined by the survey questions. However, in a few instances they were aggregated from the original categories because of small numbers. For example, the sample size was not large enough to allow a finer classification of ethnicity than white British and other. Although correlated, occupation and education measure different attributes for women, especially those in this age group, for whom occupational information is of limited value and hard to interpret. ${ }^{19} \mathrm{We}$ adjusted regression analyses for age and the above sociodemographic characteristics. We derived odds ratios and 95\% confidence intervals. We regarded $P$ values less than 0.05 as statistically significant. We present odds ratios adjusted for age only and fully adjusted odds ratios. Numerators and denominators given in the text and tables refer to the unweighted sample.

Table 1| Screening history by age group of respondent, Great Britain 2005-7

\begin{tabular}{|c|c|c|c|c|c|c|c|c|c|c|c|}
\hline \multirow{2}{*}{$\begin{array}{l}\text { Age of } \\
\text { respondent } \\
\text { (years) }\end{array}$} & \multirow{2}{*}{$\begin{array}{c}\text { No of women in } \\
\text { sample }\end{array}$} & \multicolumn{2}{|c|}{$\begin{array}{c}\text { Ever had } \\
\text { mammogram* }\end{array}$} & \multicolumn{2}{|c|}{$\begin{array}{c}\text { Ever had cervical } \\
\text { smeart }\end{array}$} & \multicolumn{2}{|c|}{$\begin{array}{l}\text { Ever had both } \\
\text { mammogram and } \\
\text { cervical smear }\end{array}$} & \multicolumn{2}{|c|}{$\begin{array}{l}\text { Ever had either } \\
\text { mammogram or } \\
\text { cervical smear, not } \\
\text { both }\end{array}$} & \multicolumn{2}{|c|}{$\begin{array}{l}\text { Never had either } \\
\text { mammogram or } \\
\text { cervical smear }\end{array}$} \\
\hline & & $\%(95 \% \mathrm{Cl})$ & No & $\%(95 \% \mathrm{Cl})$ & No & $\%(95 \% \mathrm{Cl})$ & No & $\%(95 \% \mathrm{Cl})$ & No & $\%(95 \% \mathrm{Cl})$ & No \\
\hline $40-44$ & 564 & \multicolumn{2}{|c|}{ NA } & $\begin{array}{c}94.6(91.9 \text { to } \\
96.4)\end{array}$ & 534 & \multicolumn{2}{|c|}{ NA } & \multicolumn{2}{|c|}{ NA } & \multicolumn{2}{|c|}{ NA } \\
\hline $45-49$ & 475 & \multicolumn{2}{|c|}{ NA } & $\begin{array}{c}95.7(93.2 \text { to } \\
97.3)\end{array}$ & 452 & \multicolumn{2}{|c|}{ NA } & \multicolumn{2}{|c|}{ NA } & \multicolumn{2}{|c|}{ NA } \\
\hline $50-54$ & 423 & $\begin{array}{l}91.7 \ddagger(86.6 \\
\text { to } 95.0)\end{array}$ & $179 \ddagger$ & $\begin{array}{c}92.3(88.8 \text { to } \\
94.8)\end{array}$ & 391 & $\begin{array}{c}86.7 \ddagger(81.0 \\
\text { to } 90.8)\end{array}$ & $167 \ddagger$ & $\begin{array}{c}11.2 \ddagger(7.4 \text { to } \\
16.5)\end{array}$ & $27 \ddagger$ & $\begin{array}{c}2.2 \ddagger(0.8 \text { to } \\
5.8)\end{array}$ & $4 \ddagger$ \\
\hline $55-59$ & 490 & $\begin{array}{c}94.7(92.2 \text { to } \\
96.4)\end{array}$ & 461 & $\begin{array}{c}93.1 \text { (90.4 to } \\
95.2)\end{array}$ & 452 & $\begin{array}{c}89.0 \text { (85.5 to } \\
91.7)\end{array}$ & 431 & $\begin{array}{c}9.9 \text { (7.4 to } \\
13.2)\end{array}$ & 51 & $\begin{array}{c}1.1(0.5 \text { to } \\
2.6)\end{array}$ & 8 \\
\hline $60-64$ & 450 & $\begin{array}{c}92.8(89.5 \text { to } \\
95.1)\end{array}$ & 421 & $\begin{array}{c}91.8 \text { (88.6 to } \\
94.2)\end{array}$ & 411 & $\begin{array}{c}85.5 \text { (81.4 to } \\
88.8)\end{array}$ & 386 & $\begin{array}{c}13.6(10.3 \text { to } \\
17.7)\end{array}$ & 60 & $\begin{array}{c}0.9(0.3 \text { to } \\
2.6)\end{array}$ & 4 \\
\hline $65-69$ & 391 & $\begin{array}{c}93.5(90.2 \text { to } \\
95.7)\end{array}$ & 366 & $\begin{array}{c}83.9 \text { (79.1 to } \\
87.7)\end{array}$ & 330 & $\begin{array}{c}81.9(77.0 \text { to } \\
86.0)\end{array}$ & 320 & $\begin{array}{c}13.5(10.2 \text { to } \\
17.6)\end{array}$ & 56 & $\begin{array}{c}4.6(2.7 \text { to } \\
7.9)\end{array}$ & 15 \\
\hline $70-74$ & 390 & $\begin{array}{c}90.6(87.3 \text { to } \\
93.1)\end{array}$ & 351 & $\begin{array}{c}81.3(77.2 \text { to } \\
84.8)\end{array}$ & 314 & $\begin{array}{l}77.1 \text { (72.5 to } \\
81.1)\end{array}$ & 296 & $\begin{array}{c}17.6 \text { (13.9 to } \\
22.1)\end{array}$ & 73 & $\begin{array}{c}5.2(3.4 \text { to } \\
8.1)\end{array}$ & 21 \\
\hline All & $\begin{array}{l}3183 \text { (age 40- } \\
\text { 74); } 1919 \text { (age } \\
53-74)\end{array}$ & $\begin{array}{c}92.9(91.5 \text { to } \\
94.1)\end{array}$ & $\begin{array}{c}1778 \text { (age } \\
53-74)\end{array}$ & $\begin{array}{c}91.3 \text { (90.1 to } \\
92.3)\end{array}$ & $\begin{array}{l}2884 \text { (age } \\
40-74)\end{array}$ & $\begin{array}{c}84.3(82.4 \text { to } \\
86.1)\end{array}$ & $\begin{array}{l}1600 \text { (age } \\
53-74)\end{array}$ & $\begin{array}{c}13.1 \text { (11.4 to } \\
14.9)\end{array}$ & $\begin{array}{l}267 \text { (age } \\
53-74)\end{array}$ & $\begin{array}{c}2.6(2.0 \text { to } \\
3.6)\end{array}$ & $\begin{array}{c}52 \text { (age } 53- \\
74 \text { ) }\end{array}$ \\
\hline
\end{tabular}

No refers to number of women in unweighted sample.

$\mathrm{NA}=$ not applicable.

*Women aged 53 and above should have had at least one mammogram, as women are currently first invited aged 50-52.

tWomen aged 40 and above should have had at least one cervical smear, as women are first invited in their 20 s.

$\ddagger$ Ages 53-54 only. 


\section{RESULTS}

Ninety one per cent $(2884 / 3183)$ of women aged 40-74 years reported ever having had a cervical smear, and 93\% (1778/1919) aged 53-74 years reported ever having had a mammogram (table 1). We found similarly high rates in all age groups for each screening type, except for women aged 65-69 and 70-74 years among whom a much lower percentage reported ever having had a cervical smear (84\% (330/ $391)$ and $81 \%(314 / 390))$. One in $40(52 / 1919)$ women aged 53-74 years reported never having had either breast or cervical screening, and 84\% (1600/1919) reported having had both screening types. Only $1 \%$
(12/940) of women aged 55-64 reported never having had a mammogram or a cervical smear.

Cars available to the household $(\mathrm{P}=0.01)$ and housing tenure $(\mathrm{P}=0.002)$ were both significant predictors of ever having had a mammogram, after adjustment for age and sociodemographic factors (table 2). Women in households with one car had an odds of ever having had a mammogram 1.67 (95\% confidence interval 1.06 to 2.62 ) times that of women in households with no cars, and those in households with two or more cars had an odds 2.65 (1.34 to 5.26) times that of women in households with no cars, after adjustment for all the other factors. Women who owned their home with a

Table 2 |Odds ratios of screening history (ever mammogram, ever cervical smear) by sociodemographic characteristics, Great Britain 2005-7*

\begin{tabular}{|c|c|c|c|c|c|c|}
\hline & \multirow{3}{*}{$\begin{array}{c}\text { No in sample } \dagger \text { : age } \\
53-74 / 40-74 \\
(n=1895 / 3148)\end{array}$} & \multirow{3}{*}{$\begin{array}{c}\text { No in sample†: ever } \\
\text { mammogram 53-74/ } \\
\text { ever cervical smear } 40 \text { - } \\
74(n=1754 / 2851)\end{array}$} & \multicolumn{4}{|c|}{ Odds ratio $(95 \% \mathrm{Cl})$} \\
\hline & & & \multicolumn{2}{|c|}{ Ever $v$ never mammogram (age 53-74) } & \multicolumn{2}{|c|}{ Ever $v$ never cervical smear (age 40-74) } \\
\hline & & & Age adjusted & Fully adjusted $\ddagger$ & Age adjusted & Fully adjusted $\ddagger$ \\
\hline \multicolumn{7}{|l|}{ Cars available to household } \\
\hline 0 & $462 / 674$ & $403 / 575$ & 1.00 & 1.00 & 1.00 & 1.00 \\
\hline 1 & $950 / 1459$ & $888 / 1307$ & 2.30 & 1.67 (1.06 to 2.62$)$ & 1.39 & $1.03(0.72$ to 1.46$)$ \\
\hline$\geq 2$ & $483 / 1015$ & $463 / 969$ & 3.92 & $2.65(1.34$ to 5.26$)$ & 2.58 & 1.61 (0.97 to 2.67$)$ \\
\hline$P$ value & & & & 0.01 & & 0.09 \\
\hline \multicolumn{7}{|l|}{ Housing tenure } \\
\hline Rents & $363 / 664$ & $307 / 574$ & 1.00 & 1.00 & 1.00 & 1.00 \\
\hline Owns with mortgage & $377 / 1128$ & $357 / 1069$ & 3.10 & $2.12(1.12$ to 4.00$)$ & 2.30 & $1.35(0.87$ to 2.10$)$ \\
\hline Owns outright & $1155 / 1356$ & $1090 / 1208$ & 3.04 & 2.19 (1.39 to 3.43$)$ & 1.90 & $1.25(0.89$ to 1.77$)$ \\
\hline$P$ value & & & & 0.002 & & 0.3 \\
\hline \multicolumn{7}{|c|}{ Highest level of education qualification } \\
\hline No qualifications & $902 / 1117$ & $823 / 955$ & 1.00 & 1.00 & 1.00 & 1.00 \\
\hline $\begin{array}{l}\text { Below degree level } \\
\text { (including other) }\end{array}$ & $800 / 1569$ & $749 / 1459$ & 1.37 & $1.00(0.61$ to 1.62$)$ & 2.00 & $1.48(1.03$ to 2.14$)$ \\
\hline Degree or equivalent & $193 / 462$ & $182 / 437$ & 2.29 & $1.58(0.70$ to 3.60$)$ & 2.42 & 1.78 (1.01 to 3.13$)$ \\
\hline$P$ value & & & & 0.5 & & 0.06 \\
\hline \multicolumn{7}{|c|}{ National Statistics socioeconomic classification } \\
\hline $\begin{array}{l}\text { Routine and manual } \\
\text { occupations }\end{array}$ & $839 / 1259$ & $771 / 1102$ & 1.00 & 1.00 & 1.00 & 1.00 \\
\hline Intermediate occupations & $459 / 739$ & $424 / 686$ & 0.99 & $0.71(0.42$ to 1.18$)$ & 1.92 & $1.51(1.03$ to 2.20$)$ \\
\hline $\begin{array}{l}\text { Managerial and } \\
\text { professional occupations }\end{array}$ & $538 / 1038$ & $506 / 967$ & 1.55 & $0.97(0.56$ to 1.68$)$ & 1.83 & $1.24(0.83$ to 1.85$)$ \\
\hline Not classified & $59 / 112$ & $53 / 96$ & 0.43 & $0.46(0.17$ to 1.25$)$ & 0.51 & $0.69(0.37$ to 1.28$)$ \\
\hline$P$ value & & & & 0.3 & & 0.06 \\
\hline \multicolumn{7}{|l|}{ Ethnicity } \\
\hline Other & $119 / 259$ & $105 / 222$ & 1.00 & 1.00 & 1.00 & 1.00 \\
\hline White British & $1776 / 2889$ & $1649 / 2629$ & 1.74 & $1.29(0.62$ to 2.67$)$ & 2.62 & $2.20(1.41$ to 3.42$)$ \\
\hline$P$ value & & & & 0.5 & & 0.0005 \\
\hline \multicolumn{7}{|l|}{ Region } \\
\hline North & $501 / 829$ & $464 / 759$ & 1.00 & 1.00 & 1.00 & 1.00 \\
\hline Midlands and East Anglia & $506 / 845$ & $466 / 766$ & 1.10 & $1.00(0.57$ to 1.74$)$ & 0.95 & 0.95 (0.66 to 1.38$)$ \\
\hline London & $163 / 300$ & $145 / 264$ & 0.74 & $0.78(0.40$ to 1.51$)$ & 0.55 & $0.71(0.46$ to 1.12$)$ \\
\hline South East & $280 / 443$ & $265 / 412$ & 1.42 & $1.22(0.63$ to 2.35$)$ & 1.42 & $1.28(0.76$ to 2.17$)$ \\
\hline South West & $177 / 284$ & $170 / 261$ & 2.80 & 2.37 (0.97 to 5.78$)$ & 1.15 & $1.06(0.64$ to 1.77$)$ \\
\hline Wales & $71 / 125$ & $66 / 110$ & 1.50 & 1.25 (0.48 to 3.22$)$ & 0.74 & $0.77(0.35$ to 1.70$)$ \\
\hline Scotland & $197 / 322$ & $178 / 279$ & 0.98 & 1.07 (0.60 to 1.93$)$ & 0.67 & $0.73(0.44$ to 1.19$)$ \\
\hline$P$ value & & & & 0.9 & & 0.4 \\
\hline
\end{tabular}

*35 women with missing values on sociodemographic variables omitted from analysis.

†Numbers refer to unweighted sample.

¥Adjusted for age, cars, housing tenure, highest level of education, National Statistics socioeconomic classification, ethnic group, and region. 
mortgage had an odds ratio of ever having had a mammogram of 2.12 (1.12 to 4.00), and those who owned their home outright an odds ratio of 2.19 (1.39 to 3.43), compared with women in rented housing. We found no significant associations between ever having had a mammogram and highest level of education, National Statistics socioeconomic classification, ethnicity, or region.

Only ethnicity was a significant predictor of ever having had a cervical smear after adjustment for age and sociodemographic factors $(\mathrm{P}=0.0005)$. White British women had an odds of ever having had a cervical smear 2.20 (1.41 to 3.42) times that of women of other ethnicity. Women with a degree had an odds of ever having had a cervical smear 1.78 (1.01 to 3.13) times, and those with qualifications less than a degree had an odds 1.48 (1.03 to 2.14) times, that of women with no qualifications after adjustment for age and sociodemographic variables. Women in intermediate occupations had an odds ratio of ever having had a cervical smear of 1.51 (1.03 to 2.20) compared with women in routine and manual occupations.

Although these results indicate that the significant predictors are different for breast and cervical screening, we then combined the two types of screening to enable us to investigate women who were good overall screeners (table 3). Cars $(\mathrm{P}=0.006)$, housing tenure $(\mathrm{P}=0.04)$, and education $(\mathrm{P}=0.04)$ were significant predictors of having had both breast and cervical screening compared with having had only one or neither screening type, after adjustment for age and sociodemographic factors. Ethnicity was the only statistically significant predictor when we compared women who had had some screening with those who had had none $(\mathrm{P}=0.02)$. White British women had a fully adjusted odds ratio of having had some screening versus none of 3.01 (1.22 to 7.38) compared with women of other ethnicity. However, very few women overall had never had either screen (52 women aged 53-74), so these figures are based on very small numbers.

Among the 1778 women aged 53-74 who had ever had a mammogram, $1553(87.7 \%, 95 \%$ confidence interval $85.9 \%$ to $89.3 \%$ ) had had their most recent mammogram as routine screening by the NHS Breast Screening Programme (table 4); a further 80 (4.3\%, $3.4 \%$ to $5.4 \%$ ) were non-routine referrals to the NHS, and $57(3.5 \%, 2.6 \%$ to $4.6 \%)$ were follow-ups after treatment for breast cancer. Although almost as high a percentage of women aged 70-74 had ever had a mammogram as had women in younger age groups (table 1), routine screening unsurprisingly accounted for a lower proportion of most recent mammograms in this age group whereas non-routine NHS referrals accounted for a higher proportion. These differences, however, were not significant.

Just under two thirds (1172/1919) of women aged 53-74 had had a mammogram in the previous three years, decreasing from $80 \%(154 / 198)$ of those aged $53-54$ to $58 \%(223 / 391)$ in the $65-69$ age group and $27 \%(108 / 390)$ in the 70-74 age group (fig 1). Eighty nine per cent $(600 / 688)$ of women in their 50 s had had a mammogram in the previous six years, as had $80 \%(678 / 841)$ of those in their $60 \mathrm{~s}$ and $48 \%$ (187/ 390) of the 70-74 age group. Of women who had not had a hysterectomy, around three quarters of those in each age group from 40-44 and 55-59 years had had a cervical smear in the previous five years and a further approximately $5 \%$ had one more than five years previously (fig 2). Unsurprisingly, among women aged 60 and over, the percentage who had a smear less than five years previously decreased with age; the percentage who had one longer ago increased with age, as did the percentage reporting never having had one. Most women knew when they had last had a mammogram, in contrast with the higher proportion of women who did not know the date of their most recent cervical smear.

\section{DISCUSSION}

Using survey data from a representative sample of the population of Great Britain, this study shows, for both breast and cervical screening, high rates of ever having been screened. About three in every 100 women aged 53-74, the age range eligible to have had both types of screening, reported never having had either screening type. This indicates that not participating in either
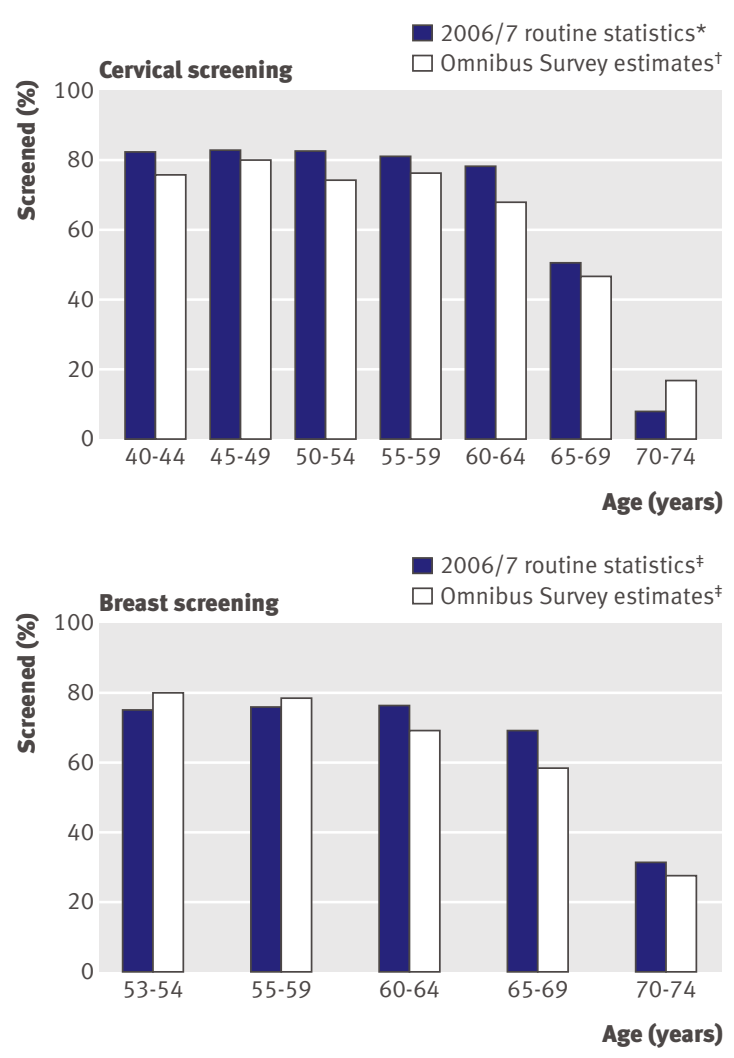

Fig 3 Percentage of women screened in most recent time period, comparing Omnibus Survey estimates with routine statistics. *Less than five years since last adequate test (women with recall ceased for clinical reasons excluded from denominator). †Less than five years since last test (women who have had hysterectomy excluded from denominator). fLess than three years since last test 
screening is rare. However, one in eight women eligible to have had both types of screening report never having had one of the screening types. Moreover, screening does not extend equally to all parts of the population. Women in households with a car were significantly more likely to have had a mammogram than those in households with no car, as were women in owner occupied housing compared with rented housing. These characteristics, which can be interpreted as indicators of household wealth (and possibly in the case of cars, mobility), were not found to be important for cervical screening. Here ethnicity was the most important predictor; white British women were signif icantly more likely to have had a cervical smear than were women in other ethnic groups. Although neither education nor occupation was associated with breast screening, cervical screening was more frequent among more educated women. Establishing the reasons behind these inequalities is beyond the scope of this analysis. However, cervical screening is usually provided locally whereas travel is generally needed to get to a mammography facility; this may tie in with the importance of cars in relation to breast, but not cervical, screening.

Table 3 |Odds ratios of screening history (ever both screenings, ever some screening) by sociodemographic characteristics, Great Britain 2005-7* Odds ratios $(95 \% \mathrm{Cl})$

\begin{tabular}{|c|c|c|c|c|c|c|}
\hline & \multirow{3}{*}{$\begin{array}{l}\text { No in samplet: age } \\
53-74(\mathrm{n}=1895)\end{array}$} & \multirow{3}{*}{$\begin{array}{l}\text { No in sample†: ever both } \\
53-74 / \text { ever some } 53-74 \\
(n=1578 / 1843)\end{array}$} & \multicolumn{4}{|c|}{ Odds ratios $(95 \% \mathrm{Cl})$} \\
\hline & & & \multicolumn{2}{|c|}{$\begin{array}{l}\text { Ever both mammogram and cervical smear } v \\
\text { not both } \ddagger(53-74)\end{array}$} & \multicolumn{2}{|c|}{$\begin{array}{c}\text { Ever mammogram, cervical smear, or both } v \\
\text { never either§ }(53-74)\end{array}$} \\
\hline & & & Age adjusted & Fully adjustedף & Age adjusted & Fully adjusted $\llbracket$ \\
\hline \multicolumn{7}{|l|}{ Cars available to household } \\
\hline 0 & 462 & $349 / 436$ & 1.00 & 1.00 & 1.00 & 1.00 \\
\hline 1 & 950 & $791 / 928$ & 1.64 & $1.31(0.95$ to 1.80$)$ & 2.73 & $1.83(0.98$ to 3.41$)$ \\
\hline$\geq 2$ & 483 & $438 / 479$ & 2.92 & 2.11 (1.34 to 3.34$)$ & 5.11 & $3.21(1.00$ to 10.26$)$ \\
\hline$P$ value & & & & 0.006 & & 0.06 \\
\hline \multicolumn{7}{|l|}{ Housing tenure } \\
\hline Rents & 363 & $267 / 342$ & 1.00 & 1.00 & 1.00 & 1.00 \\
\hline Owns with mortgage & 377 & $334 / 373$ & 2.32 & 1.60 (0.99 to 2.57$)$ & 5.08 & $2.49(0.62$ to 10.06$)$ \\
\hline Owns outright & 1155 & $977 / 1128$ & 2.07 & 1.52 (1.09 to 2.12$)$ & 2.80 & 1.51 (0.69 to 3.31$)$ \\
\hline Pvalue & & & & 0.04 & & 0.4 \\
\hline \multicolumn{7}{|c|}{ Highest level of education qualification } \\
\hline No qualifications & 902 & $720 / 866$ & 1.00 & 1.00 & 1.00 & 1.00 \\
\hline $\begin{array}{l}\text { Below degree level } \\
\text { (including other) }\end{array}$ & 800 & $685 / 786$ & 1.45 & $1.17(0.81$ to 1.69$)$ & 2.40 & $1.54(0.67$ to 3.54$)$ \\
\hline Degree or equivalent & 193 & 173/191 & 2.64 & $2.13(1.20$ to 3.80$)$ & 7.14 & 5.31 (1.06 to 26.70$)$ \\
\hline$P$ value & & & & 0.04 & & 0.1 \\
\hline \multicolumn{7}{|c|}{ National Statistics socioeconomic classification } \\
\hline $\begin{array}{l}\text { Routine and manual } \\
\text { occupations }\end{array}$ & 839 & $682 / 809$ & 1.00 & 1.00 & 1.00 & 1.00 \\
\hline Intermediate occupations & 459 & $386 / 452$ & 1.20 & $0.90(0.63$ to 1.29$)$ & 2.21 & $1.48(0.50$ to 4.35$)$ \\
\hline $\begin{array}{l}\text { Managerial and } \\
\text { professional occupations }\end{array}$ & 538 & $464 / 526$ & 1.52 & $0.98(0.66$ to 1.44$)$ & 1.82 & 0.91 (0.39 to 2.12$)$ \\
\hline Not classified & 59 & $46 / 56$ & 0.62 & $0.68(0.35$ to 1.33$)$ & 0.32 & 0.42 (0.12 to 1.42$)$ \\
\hline$P$ value & & & & 0.7 & & 0.4 \\
\hline \multicolumn{7}{|l|}{ Ethnicity } \\
\hline Other & 119 & $95 / 110$ & 1.00 & 1.00 & 1.00 & 1.00 \\
\hline White British & 1776 & $1483 / 1733$ & 1.65 & 1.51 (0.86 to 2.66$)$ & 4.11 & $3.01(1.22$ to 7.38$)$ \\
\hline$P$ value & & & & 0.1 & & 0.02 \\
\hline \multicolumn{7}{|l|}{ Region } \\
\hline North & 501 & $417 / 490$ & 1.00 & 1.00 & 1.00 & 1.00 \\
\hline Midlands and East Anglia & 506 & $428 / 486$ & 1.26 & 1.21 (0.81 to 1.81$)$ & 0.73 & 0.65 (0.28 to 1.48$)$ \\
\hline London & 163 & $132 / 155$ & 0.93 & $0.98(0.61$ to 1.57$)$ & 0.53 & $0.67(0.26$ to 1.73$)$ \\
\hline South East & 280 & $242 / 277$ & 1.42 & 1.27 (0.82 to 1.97$)$ & 2.01 & $1.50(0.40$ to 5.70$)$ \\
\hline South West & 177 & $153 / 176$ & 1.58 & $1.41(0.81$ to 2.44$)$ & 7.19 & 5.55 (0.67 to 45.73$)$ \\
\hline Wales & 71 & $55 / 70$ & 0.82 & $0.76(0.34$ to 1.73$)$ & 3.29 & 2.98 (0.39 to 22.92$)$ \\
\hline Scotland & 197 & $151 / 189$ & 0.79 & $0.85(0.52$ to 1.40$)$ & 0.77 & 0.97 (0.39 to 2.40$)$ \\
\hline
\end{tabular}

*35 women with missing values on sociodemographic variables omitted from analysis.

tNumbers refer to unweighted sample.

$\ddagger$ Compares women who have had both screening types with those who have had only one screening type or neither screening (that is, both screenings versus not both).

$\S$ Compares women who have had either or both screening types with those who have had neither screening (that is, some screening versus none).

TAdjusted for age, cars, housing tenure, highest level of education, National Statistics socioeconomic classification, ethnic group, and region. 
Table $4 \mid$ Reason for most recent mammogram (among women who had ever had a mammogram), Great Britain 2005-7. Values are percentage (number) ( $95 \%$ confidence interval) unless stated otherwise

\begin{tabular}{|c|c|c|c|c|c|c|}
\hline \multirow{2}{*}{$\begin{array}{l}\text { Reason for most recent } \\
\text { mammogram }\end{array}$} & \multicolumn{5}{|c|}{ Age of respondent (years) } & \multirow[b]{2}{*}{ All women $53-74$} \\
\hline & $53-54$ & $55-59$ & $60-64$ & $65-69$ & $70-74$ & \\
\hline $\begin{array}{l}\text { Routine screening by NHS Breast } \\
\text { Screening Programme }\end{array}$ & $\begin{array}{l}89.3(156)(83.7 \text { to } \\
93.1)\end{array}$ & $\begin{array}{l}87.2(408)(83.2 \text { to } \\
90.4)\end{array}$ & $\begin{array}{l}89.4(374)(85.6 \text { to } \\
92.2)\end{array}$ & $\begin{array}{l}91.1 \text { (330) }(87.5 \text { to } \\
93.7)\end{array}$ & $\begin{array}{c}81.4(285)(76.8 \text { to } \\
85.3)\end{array}$ & $\begin{array}{c}87.7(1553)(85.9 \text { to } \\
89.3)\end{array}$ \\
\hline $\begin{array}{l}\text { NHS screening owing to family } \\
\text { history of breast cancer }\end{array}$ & 1.9 (4) (0.7 to 5.1$)$ & $0.6(2)(0.1$ to 2.2$)$ & 0.7 (3) (0.2 to 2.2$)$ & $1.6(6)(0.7$ to 3.7$)$ & 2.2 (9) (1.0 to 4.8) & 1.3 (24) (0.8 to 1.9) \\
\hline Non-routine referral to NHS & 4.6 (9) (2.2 to 9.2) & $4.4(20)(2.6$ to 7.1$)$ & 3.3 (16) (2.0 to 5.4$)$ & 2.6 (11) (1.4 to 4.9) & 7.4 (24) (4.9 to 11.0$)$ & $4.3(80)(3.4$ to 5.4$)$ \\
\hline Private mammogram & 1.4 (3) (0.4 to 4.7) & 1.5 (6) (0.7 to 3.5$)$ & 1.7 (9) (0.8 to 3.7) & 1.1 (3) (0.3 to 3.3) & $1.6(5)(0.6$ to 4.1$)$ & 1.5 (26) (1.0 to 2.3) \\
\hline $\begin{array}{l}\text { Follow-up after treatment for breast } \\
\text { cancer }\end{array}$ & 1.4 (3) $(0.4$ to 4.7$)$ & $5.7(20)(3.6$ to 8.9$)$ & 3.5 (14) (2.0 to 5.9) & 3.5 (15) (2.0 to 6.0) & $1.3(5)(0.5$ to 3.2$)$ & $3.5(57)(2.6$ to 4.6$)$ \\
\hline Other & $1.2(3)(0.4$ to 3.8$)$ & 0.4 (3) (0.1 to 1.3$)$ & 0.3 (2) (0 to 1.4) & 0.2 (1) (0 to 1.2) & 3.1 (13) (1.7 to 5.6) & 0.9 (22) (0.6 to 1.4$)$ \\
\hline Do not know & 0.3 (1) (0 to 1.9) & $0.2(2)(0$ to 1.0$)$ & 1.1 (3) (0.3 to 3.6) & $0.0(0)$ & 3.0 (10) (1.5 to 5.8$)$ & 0.9 (16) (0.5 to 1.6$)$ \\
\hline $\begin{array}{l}\text { No who had ever had a } \\
\text { mammogram }\end{array}$ & 179 & 461 & 421 & 366 & 351 & 1778 \\
\hline
\end{tabular}

Numbers refer to number of women in unweighted sample.

Breast and cervical screening, although considered together in this paper, are different in nature and purpose; cervical cytology is done purely for screening purposes, whereas mammograms may be done either as routine screening of asymptomatic women or for diagnostic reasons. In the case of a woman's most recent mammogram, our data distinguish between those done routinely under the NHS Breast Screening Programme and those done for other reasons. Of note are the $3.5 \%$ of women who had their most recent mammogram as follow-up after treatment for breast cancer, indicating that one in 30 women aged 53-74 have been treated for breast cancer.

\section{Strengths and limitations of the study}

This survey based study has advantages over the NHS data used to produce the routine statistics on screening coverage ${ }^{56}$ It provides estimates of aspects of lifetime screening experience for all women in the age group concerned. The data are not affected by list inflation, and, moreover, the individual and household sociodemographic data collected by the Omnibus Survey provide the opportunity to investigate inequalities in screening.

The survey data do, however, have limitations. Despite the great effort made by interviewers to maximise response rates to the Omnibus Survey, more than $30 \%$ of selected people in the surveys used in this analysis declined to take part or could not be contacted. Little information is available on the nonresponders and how they differ from the responders. Weighting the data by age, sex, and region to Office for National Statistics population totals deals with aspects of non-response, but some bias may remain in the estimates if non-response varies by sociodemographic characteristics not included in the weighting. Non-contact in surveys has been shown to be associated with characteristics related to the propensity to be at home, whereas refusal is related more to individual characteristics such as socioeconomic position, qualifications, and attitudes. ${ }^{20}$
With the exception of hysterectomy, we have not been able to exclude from our analysis women who would not be invited for screening on clinical grounds (such as bilateral mastectomy in the case of breast screening). This may result in underestimation of the true prevalence of breast screening, including that within the previous three years and other time periods. As mentioned above under outcome measures, we have not excluded women who have had a hysterectomy from the analysis of ever having had cervical screening.

Although our study shows inequalities in screening, we cannot say whether these result from women being missed by the call-recall system, women failing to attend after invitation, or sociodemographic differences in recall bias or reporting. Being based on self reported information, the survey data are open to recall bias and reporting errors that may indeed vary by age, ethnicity, and socioeconomic position. Some studies have suggested that self reported data overestimate screening rates, but most research in this area relates to Australia and the United States. ${ }^{2122}$ A UK study comparing self reported cervical abnormalities with screening records showed that women are good at reporting abnormalities. ${ }^{23}$ Our findings are unlikely to be attributable to differential reporting across sociodemographic groups, as we would then expect to see similar patterns for breast and cervical screening, which we do not see. For example, if our finding of the importance of ethnicity for cervical screening was attributable to under-reporting by women in ethnic groups other than white British, we would expect to see similar ethnic differences for breast screening. Reporting on having had a mammogram may be more complete and the date of the most recent mammogram more accurate than the equivalent responses for cervical screening. A mammogram is a more memorable event requiring an appointment at a special clinic. Cervical smears, on the other hand, may be done opportunistically while a woman is having a gynaecological examination for other reasons, and 


\section{WHAT IS ALREADY KNOWN ON THIS TOPIC}

Breast and cervical screening has been shown to reduce mortality from cancer

The 2007 Cancer Reform Strategy places great emphasis on tackling inequalities in incidence, treatment, and prevention of cancer, including screening

Routine administrative data are a rich source of information on the coverage of each screening programme but cannot be used to ascertain inequalities according to individual sociodemographic characteristics

\section{WHAT THIS STUDY ADDS}

Survey data indicate that $84 \%$ of eligible women in Great Britain report having had both breast and cervical screening and 3\% report never having been screened for either

Screening does not extend equally to all segments of the population; indicators of wealth are associated with greater use of breast screening, and ethnicity is the strongest predictor of cervical screening

Routine collection of additional sociodemographic information on patients in general practice would aid monitoring of inequalities in screening coverage and inform policies to reduce them for $2006 / 7,{ }^{6}$ although they are slightly lower for all age groups except women aged 70-74, for whom our figures indicate a higher percentage having had a smear in the previous five years (fig 3 ). With the exception of the oldest women, these differences could be due to the high proportion of women in our data who did not know the date of their most recent cervical smear and a tendency for women to under-report having had cervical screening. Our data and the routine statistics on women having a mammogram in the previous three years also agree quite closely. ${ }^{5}$ These comparisons with the routine statistics provide encouraging validation of the Omnibus Survey data.

Our findings apply directly to Great Britain and the way that the breast and cervical screening programmes are organised in Great Britain. The findings may be relevant in other settings, but we are not in a position to know.

\section{Implications for practice and policy}

In showing inequalities in screening, this study highlights the importance of ensuring that the provision and uptake of screening services reach all parts of the population. This is in line with current government priorities as outlined in the Cancer Reform Strategy published in 2007 , which placed great emphasis on tackling inequalities in incidence and mortality, treatment, and prevention of cancer, including screening. ${ }^{15}$ The document drew attention, in particular, to the lack of data for demonstrating and understanding existing inequalities and the need to promote research to fill gaps in the evidence. This study is important in both respects. It provides new evidence on inequalities in screening, showing that they are characterised by indicators of household wealth in the case of breast screening and ethnicity in the case of cervical screening. It therefore also shows the need for information on patients' ethnicity and some indicator of their socioeconomic position to be collected routinely in general practice. This would facilitate the routine monitoring of coverage of screening among different ethnic and socioeconomic groups and could be used to inform policies to reduce inequalities in coverage.

The Omnibus Survey is carried out by the Office for National Statistics (ONS); the ONS Omnibus Survey team bears no responsibility for this analysis and interpretation of the data.

Contributors: All the authors developed the idea for the study. KM analysed the data and wrote the first draft of the paper. All authors contributed to interpreting the data and to developing and writing subsequent drafts. All authors approved the final manuscript. KM is the guarantor.

Funding: This research was supported by the NHS Breast Screening Programme and Cancer Research UK. The funders had no involvement in this research.

Competing interests: JP is director of the NHS Breast Screening Programme, and VB is chairman of the Advisory Committee on Breast Cancer Screening.

Ethical approval: Not needed. in their 50s (that is, past reproductive ages and therefore less likely to have opportunistic smears) in 1990 when the screening programme became more comprehensive. Our estimates of the proportion of women who had had a cervical smear in the previous five years match quite closely the routine coverage statistics
1 International Agency for Research on Cancer. Breast cancer screening. Lyon: IARC Press,

2002. (IARC Handbooks of Cancer Prevention, volume 7.)

2 Advisory Committee on Breast Cancer Screening. Screening for breast cancer in England: past and future. Sheffield: NHS Cancer 
Screening Programmes,

2006. (NHS Breast Screening Programme publication No 61.)

3 Hakama M, Louhivouri K. A screening programme for cervical cance that worked. Cancer Surv 1988;7:403-15.

4 Quinn M, Babb P, Jones J, Allen E. Effect of screening on incidence of and mortality from cancer of cervix in England: evaluation based on routinely collected statistics. BMJ 1999;318:904-8.

5 NHS Health and Social Care Information Centre. Breast Screening Programme, England: 2006-07. Leeds: The Information Centre, 2008.

6 NHS Health and Social Care Information Centre. Cervical Screening Programme, England: 2006-07. Leeds: The Information Centre, 2007.

7 Raleigh VS. Collection of data on ethnic origin in England. BMJ 2008;337:645-6.

8 Fell G, Gregory L. Equality review: national screening programmes: a scoping report for the National Screening Committee. London: National Screening Committee, 2007.

9 Sutton S, Rutherford C. Sociodemographic and attitudinal correlates of cervical screening uptake in a national sample of women in Britain. Soc Sci Med 2005;61:2460-5.

10 Sabates R, Feinstein L. The role of education in the uptake of preventative health care: the case of cervical screening in Britain. Soc Sci Med 2006;62:2998-3010.

11 Banks E, Beral V, Cameron R, Hogg A, Langley N, Barnes I, et al. Comparison of various characteristics of women who do and do not attend for breast cancer screening. Breast Cancer Res 2002;4(1):R1.

12 Maheswaran R, Pearson T, Jordan H, Black D. Socioeconomic deprivation, travel distance, location of service, and uptake of breast cancer screening in North Derbyshire, UK. J Epidemiol Community Health 2006;60:208-12.
13 Moser KA, Naish J, Chambers MG. Cervical smear uptake rates [correction at BMJ 1994;309:674]. BMJ 1994;309:476-7.

14 Chiu LF. Inequalities of access to cancer screening: a literature review. Sheffield: NHS Cancer Screening Programmes, 2003. (Cancer Screening Series No 1.)

15 Department of Health. Cancer reform strategy. London: DH, 2007.

16 Ashworth M, Jenkins M, Burgess K, Keynes H, Wallace M, Roberts D, et al. Which general practices have higher list inflation? An exploratory study. Fam Pract 2005;22:529-31.

17 Millett C, Bardsley M, Binysh K. Exploring the effects of population mobility on cervical screening coverage. Public Health 2002;116:353-60.

18 Office for National Statistics. Omnibus survey. www.ons.gov.uk/ about/who-we-are/our-services/omnibus-survey/index.html.

19 Moser KA, Pugh HS, Goldblatt PO. Inequalities in women's health: looking at mortality differentials using an alternative approach. $B M$ 1988;296:1221-4

20 Durrent GB, Steele F. Multilevel modelling of refusal and noncontact nonresponse in household surveys: evidence from six UK government surveys. Southampton, UK: University of Southampton, 2007 (available from http://eprints.soton.ac.uk/46013/).

21 McGovern PG, Lurie N, Margolis KL, Slater JS. Accuracy of self-report of mammography and Pap smear in a low-income urban population. Am J Prev Med 1998;14:201-8.

22 Bowman JA, Sanson-Fisher R, Redman S. The accuracy of selfreported Pap smear utilisation. Soc Sci Med 1997;44:969-76.

23 Canfell K, Beral V, Green J, Cameron R, Baker K, Brown A. The agreement between self-reported cervical smear abnormalities and screening programme records. J Med Screen 2006;13:72-5.

Accepted: 6 February 2009 